mortalidade e violência. Entretanto, quando o enfoque privilegia, de fato, uma perspectiva de gênero, não apenas aparecem as contraposições ao feminino, mas também ao próprio modelo hegemônico de masculinidade. E é neste sentido que Kimmel chama a atenção para o fato de que a masculinidade se constrói não só em relação ao feminino, mas também em relação ao próprio grupo de pares e a diferentes modelos masculinos, inclusive à homossexualidade. Assim, a grande maioria dos trabalhos na área da Saúde Coletiva opera ainda com a perspectiva de uma masculinidade hegemônica, sem considerar a existência de diferentes tipos de masculinidades.

Um outro aspecto que deve ser questionado a partir da perspectiva de gênero é que esta abordagem não se restringe a incluir os homens nos estudos e formulação de políticas públicas, mas implica uma mudança na forma de abordar as questões de saúde e de prevenção. Ou seja, esta perspectiva impõe uma abordagem centrada no caráter relacional e, portanto, não basta incluir os homens, mas a própria forma de trabalhar com as mulheres deve ser repensada. O eixo das reflexões e intervenções deixa de ser o individuo (homem ou mulher) e passa a ser as relações e representações sociais acionadas nestes contextos.

A dificuldade em dar conta destas implicações aparece claramente no artigo quando os autores acionam uma concepção de saúde e de cuidado intensamente marcada pela concepção biomédica. Concepção esta que não contempla outras possibilidades de pensar o cuidado de si e do outro fora das formas tradicionais, com as quais as mulheres são fortemente identificadas. É assim que os homens são percebidos como não-socializados para o cuidado e a valorização da saúde. Será que ao contemplarmos as questões de gênero o cuidado não adquire também um outro significado? Ou seja, será que, por exemplo, as estratégias acionadas pelos homens face a determinadas situações - tais como as relações sexuais com as "mulheres de rua" ou "perigosas" - não podem ser pensadas como um cuidado de si, embora se encontrem distante do modelo preconizado pelo discurso biomédico? $\mathrm{E}$ todos os esforços despendidos à manutenção da própria masculinidade não podem também ser incluídos na categoria do cuidado e, nesse caso, não apenas de si mas também do outro?

Assim, antes de excluir os homens das categorias de cuidado e saúde faz-se necessário pensar nas significações que estas categorias adqui- rem no universo masculino. E, neste sentido, a perspectiva de gênero pode contribuir para o questionamento das categorias e práticas tradicionais da área da saúde, permitindo, com isso, conhecer outras formas de se relacionar com a mesma que escapam às suas prescrições. Incluir os homens nos estudos deve propiciar uma mudança de perspectiva e não apenas de universo de investigação.

\section{Saúde do homem: uma nova etapa da medicalização da sexualidade?}

Man's health: a new stage of

medicalization of sexuality?

\section{Estela Maria Leão de Aquino ${ }^{3}$}

Durante muito tempo, as diferenças entre os sexos no adoecimento e na morte foram consideradas naturais e as explicações, quando buscadas, apoiavam-se na biologia - ciência pretensamente neutra e objetiva. Isso orientou toda a construção de conhecimentos científicos e tecnológicos na área de saúde (Krieger \& Fee, 1994). As diferenças mais evidentes eram ligadas ao aparelho reprodutivo, o que incluía não só doenças - por exemplo, as mulheres acometidas por neoplasias de colo de útero e os homens pelo câncer de próstata -, mas também um conjunto de eventos relativos à menstruação, à gestação, ao parto e ao puerpério, restritos obviamente às mulheres. Muitas outras doenças, como as cardiovasculares, apresentavam distribuição diferente entre mulheres e homens, mas isso podia ser explicado pela maior proteção hormonal das primeiras ou pelo estresse naturalmente maior dos últimos. A infância e a velhice eram (e ainda o são) descritas sem sexo. Na saúde ocupacional, essa variável tampouco era usada, porém a produção de conhecimentos e as intervenções voltavam-se aos homens, sendo as mulheres - sempre potencialmente grávidas - lembradas apenas para a proteção ao feto.

A partir da década de 1980, o que parecia óbvio passou a ser questionado por influência

3 MUSA-Programa de Estudos em Gênero e Saúde do Instituto de Saúde Coletiva da Universidade Federal da Bahia.estela@ufba.br 
do feminismo no âmbito acadêmico e nas políticas públicas. Uma das críticas mais contundentes dizia respeito ao modo como homens e mulheres eram representados na literatura biomédica: o masculino como norma e o feminino como "outro", especial, desviante (Krieger \& Fee, 1994). E desse modo, ao se ocultar a masculinidade implícita do ser humano universal, apresentado sempre com aparente neutralidade, reafirmava-se as bases da discriminação.

A forte crítica ao essencialismo da biomedicina visava, em um primeiro momento, retirar as mulheres da esfera exclusiva da reprodução, conferindo visibilidade a inúmeras necessidades de saúde negligenciadas até então como resultado do chamado viés de gênero nas ciências biomédicas. Isso gerou uma enorme quantidade de estudos e proposições voltados à saúde das mulheres e suas especificidades. No Brasil, a expressão mais emblemática desses esforços foi a criação do PAISM - Programa de Assistência Integral à Saúde da Mulher, que ainda hoje se constitui em uma referência para o movimento feminista pela saúde. O aprofundamento da reflexão feminista desembocou nos estudos de gênero que vêm proliferando em todo o mundo ocidental. Sua aplicação na Saúde Coletiva tem apresentado benefícios inegáveis permitindo repensar estratégias metodológicas, conceitos e categorias analíticas, incluir novas temáticas como a violência e a sexualidade, e voltar a estudar antigas - como o trabalho e a reprodução.

Os estudos sobre homens e masculinidades têm trazido contribuições importantes ao problematizar aspectos cruciais para reflexão sobre a dominação masculina e as relações de gênero. Ao partir da noção de masculinidade hegemônica, a produção teórica e empírica neste campo tem permitido o reconhecimento de masculinidades múltiplas e contribuído para pensar o gênero como categoria que atravessa o tecido social e se articula à classe, raça/etnia e geração, recriando formas de subordinação e opressão. $\mathrm{Na}$ área de saúde, tem-se buscado demonstrar como a "masculinidade hegemônica" gera comportamentos danosos à saúde, o que fica evidente no artigo "Homens e saúde na pauta da Saúde Coletiva”. Essa ampla revisão, que certamente será uma referência para aqueles que pretendem se introduzir ao tema, abrange variados aspectos e poderia suscitar diferentes questões para o debate. Considerando sua inserção em suplemento que pretende colocar a "Saúde do homem em questão", parece conveniente examinar as implicações de se adotar es- sa expressão em abordagem complementar e análoga à tradicional saúde da mulher.

Antes de tudo, é preciso esclarecer que essa última expressão não foi cunhada pelo feminismo, mas pelos médicos. Suas origens remontam ao século 19, quando se constituíram as bases da ginecologia moderna, como uma "ciência da mulher", sem qualquer equivalente em relação ao homem (Rohden, 2001). Isso ocorreu em um contexto histórico de grandes transformações sociais, em que as mulheres reivindicavam novos direitos ao voto, à educação e ao trabalho e a medicina produzia os argumentos que justificassem as relações hierárquicas nas quais elas ocupavam o pólo dominado. Durante o século 20 , houve uma medicalização progressiva do corpo feminino, como parte do processo mais amplo de normatização da vida social pela medicina (Vieira, 2002; Rohden, 2001). Nos anos 70/80, o termo saúde da mulher foi resgatado pelas feministas com o propósito de ressignificá-lo para conferir visibilidade às necessidades das mulheres para além da função materna, em oposição à perspectiva materno-infantil em que o interesse primordial recaía na saúde do feto e da criança. $O$ principal problema ao adotar essa expressão prende-se à ênfase nas especificidades - o que reafirma a representação simbólica da diferença sexual como a ordem natural do mundo, mantendo a mulher como ser essencial ahistórico e universal.

Todavia, como poderiam as mulheres, discriminadas com base na sua diferença, exigir mudanças como indivíduos humanos sem invocar a diferença que as excluiu? Como a discriminação, que atribuía características de grupo a indivíduos com base no seu sexo, poderia ser combatida sem que se levantasse a questão da diferença sexual? Como a questão da diferença sexual poderia ser levantada sem que se reproduzissem os termos nos quais a exclusão se baseia? (Scott, 2001). Esse "essencialismo estratégico" não é ingênuo e tem sido objeto de sérias discussões, não apenas no feminismo, mas no âmbito de outras lutas identitárias (por exemplo, nas propostas de cotas para negros e nos questionamentos quanto a ganhos e perdas políticas com a "racialização" da sociedade).

E o que dizer então da emergência do termo saúde do homem? Quais as suas origens e que forças têm contribuído para sua institucionalização?

$\mathrm{Na}$ base Medline - principal base de referências bibliográficas sobre saúde -, a expressão no singular não é encontrada e o termo men's 
health não integra os descritores - ao contrário de women's health, incorporado em 1991. A mais antiga das 307 referências identificadas a partir da expressão men's health em qualquer campo de busca é de 1984, sendo uma revisão sobre diferenças entre os sexos na morbi-mortalidade (Wingard, 1984). Até 1994, todos os artigos tratavam da infecção pelo HIV e a Aids, parte significativa dos quais tratando de homens gays e muitas vezes em diálogo com a literatura feminista. Em 1996, men's health intitulava um editorial do British Medical Journal (Griffiths, 1996), em que eram destacados os variados condicionantes da saúde dos homens, os quais comparativamente às mulheres teriam menor capacidade de reconhecer problemas físicos e emocionais e procurar ajuda.

Ao final da década de 1990, um "novo" problema de saúde surge associado ao termo: a disfunção erétil (Montorsi, 2004; Potts et al., 2004). Essa "desordem" é definida na literatura médica como a incapacidade de obter ou manter uma ereção peniana suficiente para uma relação sexual satisfatória (Potts et al., 2004) e até então era tratada por psicoterapia ou pelo uso de implantes ou bombas penianas. É quando se registra a ocorrência de ereções penianas como efeito colateral inesperado de um medicamento - o citrato de sildenafil - destinado ao tratamento de problemas cardiovasculares (Montorsi, 2004). $\mathrm{O}$ advento do Viagra ${ }^{\circledR}$, nome pelo qual a droga foi comercializada, promoveu uma mudança na abordagem terapêutica da disfunção erétil, desencadeando inúmeros estudos - financiados em grande parte pela indústria farmacêutica -, a difusão massiva na mídia e uma demanda sem precedentes por tratamento médico especializado.

A primeira década deste século é ocupada por publicações sobre drogas hormonais. Ao lado do interesse sobre a disfunção erétil, constata-se uma profusão de indicações terapêuticas de reposição hormonal para o tratamento da andropausa ou climatério masculino, o que provoca em leitores desavisados uma sensação inevitável de dejá vu. Em 2001, registram-se mais dois editoriais: um no Journal of General Internal Medicine (Penson \& Krieger, 2001), que dedica boa parte do texto ao problema "emergente" da disfunção erétil. O segundo é um novo editorial no British Medical Journal (Baker, 2001), defendendo a articulação de iniciativas regionais em torno da proposta de men'health e anunciando o 1st World Congress on Men's Health \& Gender, nesse mesmo ano, em Viena. O evento reuniu 400 cientistas e profissionais de saúde de 17 países (http://www.wcmh.info/), tendo em sua abertura conferência do dr. Alexandre Kalache, coordenador da área de envelhecimento na Organização Mundial da Saúde (OMS). Em seu discurso, reconhecendo a impossibilidade de pensar o envelhecimento humano sem adotar a perspectiva de gênero, Kalache critica, entretanto, a ênfase exclusiva conferida às mulheres tanto na investigação científica quanto na assistência à saúde. Entre vários aspectos, chama a atenção o breve comentário de que a terapia de reposição hormonal pode ajudar a prevenir o previnivel e retardar o inevitável (Kalache, 2001), sendo necessário produzir evidências sobre seus efeitos em homens de modo complementar ao que se sabe sobre as mulheres. Em 2002, a segunda edição do evento contou com 700 participantes de 72 nações (http:// www.wcmh.info/). Desde então esses congressos têm sido realizados anualmente por associações médicas, com o apoio de quatorze grandes corporações da indústria farmacêutica, todas elas envolvidas com a produção de drogas hormonais e outros insumos para o tratamento da disfunção erétil.

Alguns artigos vêm debatendo a medicalização das disfunções sexuais masculinas e destacando como esse processo é permeado de representações de gênero e sexualidade que reforçam o modelo hegemônico de masculinidade (Winton, 2000; Loe, 2001; Bass, 2001; Potts et al., 2004). Potts et al. (2004), a partir de um estudo na Nova Zelândia com usuários de Viagra $^{\circledR}$ e suas parceiras, discutem as bases desse modelo e suas implicações nas condutas médicas, que tomam a "diversidade" como "disfunção". Segundo essas autoras, os depoimentos dos informantes contrastam fortemente com os conteúdos publicitários da indústria farmacêutica, evidenciando múltiplas possibilidades de exercício da sexualidade, em que o tratamento medicamentoso nem sempre é necessário ou exitoso.

Não se trata de recusar o desenvolvimento científico e tecnológico e o acesso universal a quem possa dele se beneficiar. Entretanto, como é discutido por Collier \& Iheanacho (2002), os interesses da indústria farmacêutica convergem em última instância para a produção de mais valia e seus programas de pesquisa sobre novas drogas se baseiam em predições de futuros mercados e no potencial de criação de produtos lucrativos. Os investimentos nas campanhas promocionais dos produtos são por vezes maiores do que na própria produção, e essas se 
dirigem, não apenas ao público potencialmente consumidor, mas antes de tudo aos médicos, que deverão ser os principais agentes na difusão dos produtos. Isso envolve múltiplas estratégias voltadas à grande mídia, mas principalmente aos veículos de divulgação científica, ou seja, congressos e periódicos. Não por acaso, os autores (Collier \& Iheanacho, 2002) citam como ilustração desses mecanismos o apoio da Pfizer - empresa farmacêutica que produz o Viagra ${ }^{\circledR}$ - ao Men's Health Fórum (http://www.menshealthforum.org.uk).

Homens e mulheres apresentam muitas diferenças, mas ao compartilharem o mesmo contexto sociocultural podem ter mais semelhanças entre si do que se comparados, respectivamente a outros homens e mulheres de diferentes grupos sociais, o que torna obrigatório contextualizar achados empíricos e articular gênero com outras categorias analíticas, como classe social, raça/etnia e geração. Rigorosamente, poucas diferenças biológicas justificam assistência especializada e ainda assim as especialidades médicas devem ser integradas, no sentido de assegurar a integralidade da atenção. Mesmo na saúde reprodutiva tem-se proposto a incorporação dos homens nas consultas de pré-natal, no momento do parto e nos serviços de contracepção. Sendo assim, na organização da atenção à saúde, enfatizar as especificidades pode reiterar o essencialismo; mas incorporar a perspectiva de gênero pode contribuir para adequar os serviços às necessidades de homens e mulheres e superar mecanismos e atitudes de discriminação. Isso pode envolver ações e estratégias voltadas a grupos de homens ou de mulheres em particular, sem a segmentação de espaços e novas especialidades.

Com um atraso histórico em relação a outras áreas do conhecimento, a Saúde Coletiva vem se abrindo à incorporação das análises de gênero sobre variados aspectos da saúde. Isso não se dá sem controvérsias ou simplificações (por exemplo, com a mera substituição de sexo por gênero em muitos estudos epidemiológicos). Existe hoje uma vasta e rica literatura produzida não apenas por distintas correntes do feminismo, mas também oriunda dos estudos críticos sobre masculinidades e das vertentes construtivistas dos estudos sobre sexualidade. Iniciativas como a organização desse suplemento e dessa seção de debates podem enriquecer a reflexão sobre gênero e saúde. Mas é preciso recusar o essencialismo - seja biológico ou cultural - e politizar as necessidades de saú- de na melhor tradição da Saúde Coletiva latino americana.

\section{Referências bibliográficas}

Baker P 2001. The international men's health movement [Editorial]. British Medical Journal 323: 1014-1015.

Bass BA 2001. The sexual performance perfection industry and the medicalization of male sexuality. Family Journal Counseling \& Therapy for Couples \& Families 9(3): 337-340.

CollierJ \& Iheanacho I 2002. The pharmaceutical industry as an informant. The Lancet 360 (November):14051409.

Griffiths S 1996. Men's health: unhealthy lifestyles and an unwillingness to seek medical help [Editorials]. British Medical Journal 312: 69-70.

Kalache A 2001. Men's health: North-South prospects, pp. 47-48. Abstract book. 1st World Congress on Men's Health \& Gender. Vienna, Austria, November 2-4.

Krieger N \& Fee E 1994. Man-made medicine and women's health: the biopolitics of sex/gender and race/ethnicity. International Journal of Health Services 24(2): 265-283.

Loe M 2001. Fixing broken masculinity: Viagra as a technology for the production of gender and sexuality. Sexuality \& Culture: an Interdisciplinary Quarterly 5(3):97-125.

Montorsi F 2004. Oral pharmacotherapy for erectile dysfunction: a personal view of experiences with three different drugs [Editorial]. Journal of Men's Health \& Gender 1(1):29-31.

Penson D \& Krieger JN 2001. Men's health: are we missing the big picture? Journal of General Internal Medicine 16(10):717.

Potts A, Grace V, Gave N \& Vares T 2004. "Viagra stories": challenging 'erectile dysfunction'. Social Science \& Medicine 59: 489-499.

Rohden F 2001. Uma ciência da diferença: sexo e gênero na medicina da mulher. Rio de Janeiro: Fiocruz. [Antropologia e Saúde]

Schraiber L, Gomes R \& Couto M 2005. Homens e saúde na pauta da Saúde Coletiva. Ciência e Saúde Coletiva 10(1):7-17.

Scott JW 2001. "La querelle des femmes" no final do século XX. Estudos Feministas 9(2):367-388.

Vieira EM 2002. A medicalização do corpo feminino. Fiocruz. Rio de Janeiro. (Antropologia e Saúde).

Wingard DL 1984. The sex differential in morbidity, mortality, and lifestyle. Annu Rev Public Health 5: 433458. (Review)

Winton MA 2000. The medicalization of male sexual dysfunctions: an analysis of sex therapy journals. Journal of Sex Education \& Therapy 25(4):231-239. 